\title{
Commercial Design of Custom Front- End Electronics for a High Temperature Fission Chamber
}

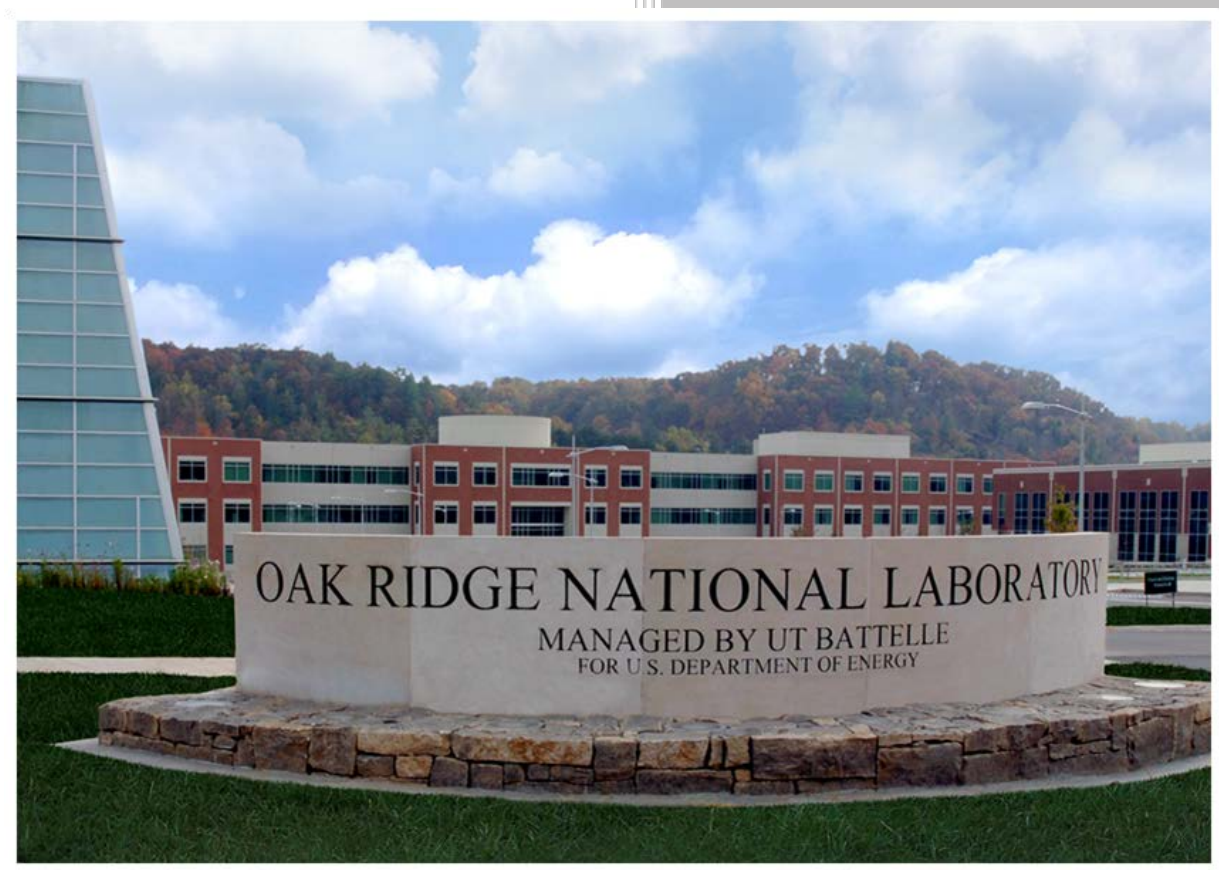

Approved for public release. Distribution is unlimited.

N. Dianne Bull Ezell Lorenzo Fabris Richard Wunderlich Pat Mulligan Christrian Petrie Charles Britton

August 2018 


\title{
DOCUMENT AVAILABILITY
}

Reports produced after January 1, 1996, are generally available free via US Department of Energy (DOE) SciTech Connect.

\section{Website http://www.osti.gov/scitech/}

Reports produced before January 1, 1996, may be purchased by members of the public from the following source:

\author{
National Technical Information Service \\ 5285 Port Royal Road \\ Springfield, VA 22161 \\ Telephone 703-605-6000 (1-800-553-6847) \\ TDD 703-487-4639 \\ Fax 703-605-6900 \\ E-mail info@ntis.gov \\ Website http://classic.ntis.gov/
}

Reports are available to DOE employees, DOE contractors, Energy Technology Data Exchange representatives, and International Nuclear Information System representatives from the following source:

Office of Scientific and Technical Information

PO Box 62

Oak Ridge, TN 37831

Telephone 865-576-8401

Fax 865-576-5728

E-mail reports@osti.gov

Website http://www.osti.gov/contact.html

This report was prepared as an account of work sponsored by an agency of the United States Government. Neither the United States Government nor any agency thereof, nor any of their employees, makes any warranty, express or implied, or assumes any legal liability or responsibility for the accuracy, completeness, or usefulness of any information, apparatus, product, or process disclosed, or represents that its use would not infringe privately owned rights. Reference herein to any specific commercial product, process, or service by trade name, trademark, manufacturer, or otherwise, does not necessarily constitute or imply its endorsement, recommendation, or favoring by the United States Government or any agency thereof. The views and opinions of authors expressed herein do not necessarily state or reflect those of the United States Government or any agency thereof. 
Electrical and Electronics System Research Division

\title{
COMMERCIAL DESIGN OF CUSTOM FRONT-END ELECTRONICS FOR A HIGH TEMPERATURE FISSION CHAMBER
}

\author{
N. Dianne Bull Ezell \\ Lorenzo Fabris \\ Richard Wunderlich \\ Pat Mulligan \\ Christrian Petrie \\ Charles Britton
}

Date Published: August 2018

Prepared by

OAK RIDGE NATIONAL LABORATORY

Oak Ridge, TN 37831-6283

managed by

UT-BATTELLE, LLC

for the

US DEPARTMENT OF ENERGY

under contract DE-AC05-00OR22725 



\section{CONTENTS}

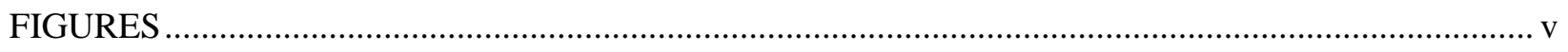

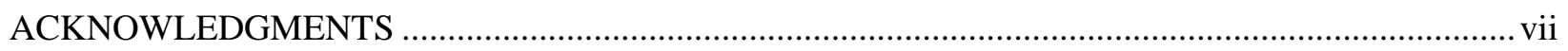

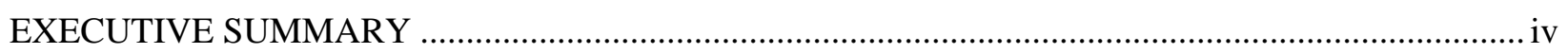

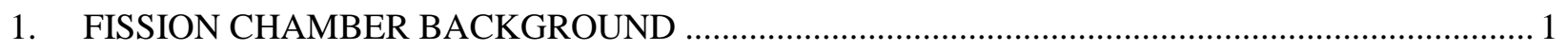

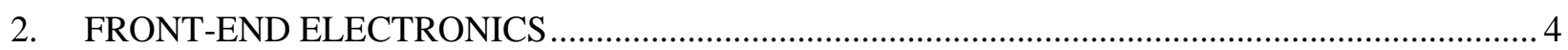

3. RECOMMENDATIONS FOR COMMERCIALIZATION .............................................................. 8

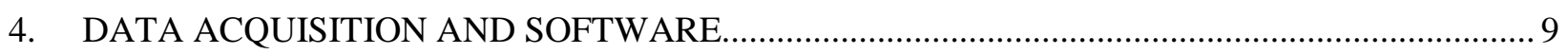

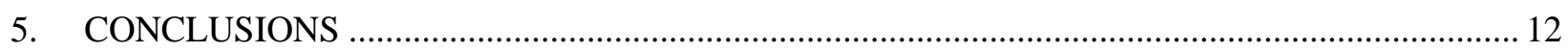

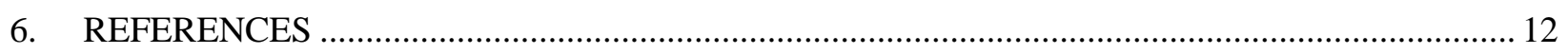





\section{FIGURES}

Figure 1. Cross-section illustration of the ORNL fission chamber.......................................................... 1

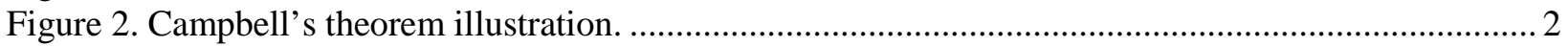

Figure 3. Block diagram of the fission chamber with front-end electronics system [1] ........................... 3

Figure 4. Simplified schematic of the chamber with proposed logarithmic charge-sensitive

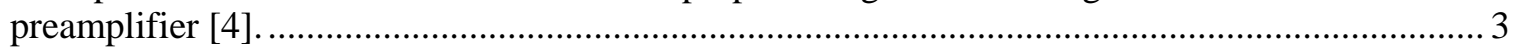

Figure 5. Simulation of logarithmic preamplifier. ................................................................................ 4

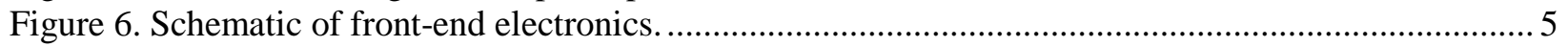

Figure 7. PSpice simulations of electronics with commercial fission chamber......................................... 6

Figure 8. PCB layout of custom front-end electronics.......................................................................... 7

Figure 9. Image of housing containing front-end electronics. .............................................................. 7

Figure 10. Testing fission chamber performance at ORNL with an AmLi source (100 ft cable)

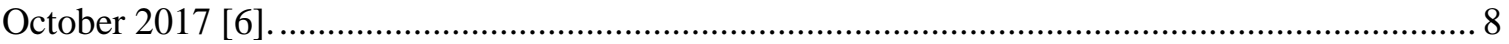

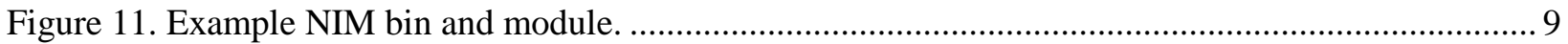

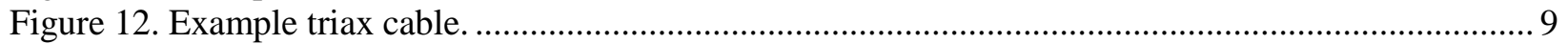

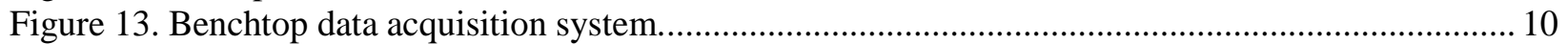

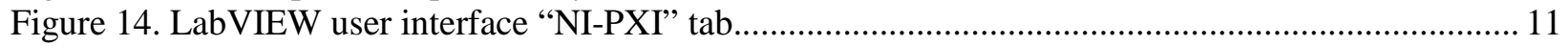

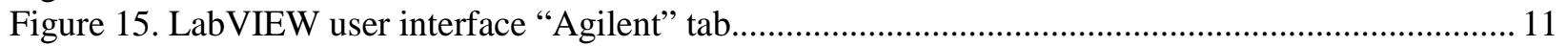





\section{ACKNOWLEDGMENTS}

This work is funded by the US Department of Energy Office of Nuclear Energy under the Advanced Reactor program. 



\section{EXECUTIVE SUMMARY}

The next generation of advanced nuclear reactors will require instrumentation designed to withstand higher temperatures and harsher environments. One of the most important instruments required to monitor power and in-core fuel management is a fission chamber. A fission chamber consists of a gas-filled chamber with a fissile coating on the inside of the chamber. When a neutron is absorbed by the fissile material, fission occurs, which produces energetic fission fragments that split off and travel in opposite directions. The fission fragments travel into the gas region of the chamber and produce a path of ionized particles. The charged particles drift to the oppositely charged electrode because of the high voltage that is applied to the cylinders of the chamber. The electronics, which convert the individual charge bunches to voltage pulses, detect and measure the charges because the rate of charge formation is an accurate measure of the number of fission events and, therefore, reactor power. The fission chamber has four regions of operation: pulse mode - (1) low flux, low temperature and (2) low flux, high temperature; current mode - (3) high flux, low temperature and (4) high flux, high temperature. Since the fission chamber is designed to operate across wide power ranges, it needs to be able to distinguish not only individual pulses at low fission rates, but also the high-rate-of-arrival pulses that pile up and are only measurable as a continuous current. The custom front-end electronics were designed to operate in both modes and all four regions. The high temperature fission chamber prototype and associated instrumentation commercialization development were completed in fiscal year 2018. 



\section{FISSION CHAMBER BACKGROUND}

The Oak Ridge National Laboratory (ORNL) high temperature fission chamber (HTFC) is an ionization chamber with three concentric electrodes that act as parallel plate capacitors as shown in Figure 1. A fission chamber consists of a gas-filled chamber with a fissile coating on the inside of the chamber. When a neutron is absorbed by the fissile material, fission occurs, which produces energetic fission fragments that are emitted from the coating. The fission fragments travel into the gas region of the chamber and produce a path of ionized particles. The resultant charged particles drift to the oppositely charged electrode because of the high voltage that is applied to the cylinders of the chamber. Assembling multiple cylinder electrodes concentrically in this topology allows for increased neutron detection sensitivity, which is important at low flux. The outermost and innermost cylinders are connected to each other, and positive high voltage (with respect to the other two cylinders) is applied to the center cylinder. This creates an electric field where the ionized particles (electrons) drift to the more positive center electrode. The center electrode is connected to readout electronics that convert the drifting charges into a voltage, which can then be further processed.

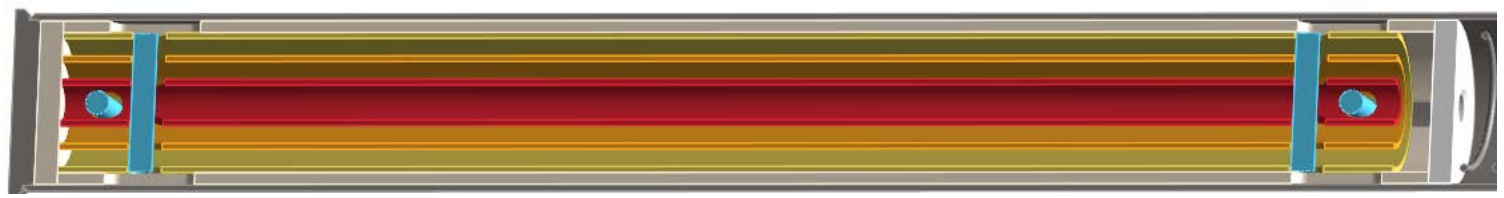

Figure 1. Cross-section illustration of the ORNL HTFC.

Since the chamber operates across a wide range of neutron flux (from $1 \mathrm{n} / \mathrm{cm}^{2} / \mathrm{s}$ to greater than $10^{9} \mathrm{n} / \mathrm{cm}^{2} / \mathrm{s}$ ), several techniques have been developed to accommodate the wide dynamic range [1]. The electronics monitor for individual pulses at low flux levels and for a continuum of pulses that appear as a continuous current at higher flux levels. A mathematical description of the issue can be developed using Campbell's theorem (illustrated in Figure 2) which states "A system whose input is a Poisson-distributed signal in time with a mean rate of $\lambda$ and whose impulse response is $h(t)$ has an output mean and variance given by

$$
\overline{\mathrm{V}}_{\mathrm{s}}=\lambda \int_{-\infty}^{\infty} \mathrm{h}(\mathrm{t}) \mathrm{dt},
$$

and

$$
\sigma_{\mathrm{s}}^{2}=\lambda \int_{-\infty}^{\infty} \mathrm{h}^{2}(\mathrm{t}) \mathrm{dt}
$$

where $\overline{V_{s}}$ is the resultant mean voltage and $\sigma_{s}^{2}$ is the square of the variance” [1, 2]. Assuming for our purposes the detector is connected to a simple resistor-capacitor network with impulse response $h(t)$, the pulse height of the individual event can be determined since the charge generated is proportional to the energy deposited in the detector medium by the incident particle. This assumes that $1 / \lambda \gg \tau \gg t_{c}$ (with $\tau$ being the time constant of the resistor-capacitor circuit, and $t_{c}$ the detector charge-collection time). The rate can be determined by counting the number $(n)$ of pulses with amplitude above a threshold, over a known period $(T)$ and deriving $\lambda$ from

$$
\lambda=\frac{n}{T}
$$




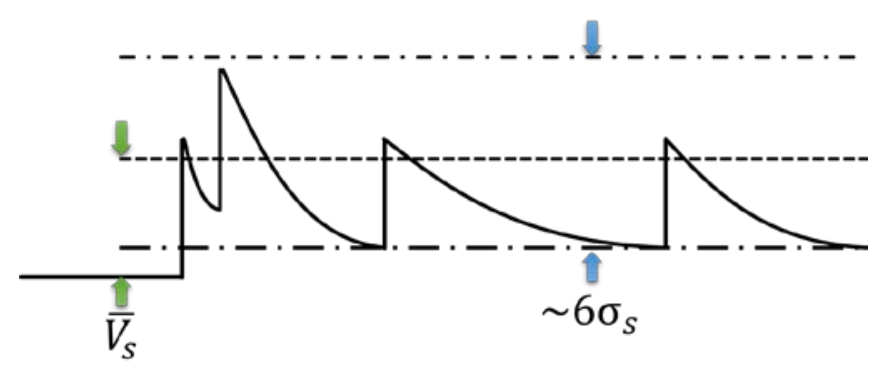

Figure 2. Campbell's theorem illustration.

As the reactor power and flux increases, the pulse rate will increase, and pulses will eventually build up and create a "pile-up" effect. The front-end electronics are therefore required to operate in both low rate (pulse) and high rate (current) modes. Campbell's theorem for the mean and variance then becomes

and

$$
\bar{V}_{S}=\lambda \int_{-\infty}^{\infty} h(t) d t=\frac{Q}{C} \lambda \int e^{-\frac{t}{\tau}} d t=Q \lambda R=\bar{I} R,
$$

$$
\sigma_{S}^{2}=\lambda \int_{-\infty}^{\infty} h^{2}(t) d t=\frac{Q^{2} \lambda \tau}{2 C^{2}}
$$

where the value of $Q \lambda$ is simply the mean current from the detector so that the voltage across the resistor is proportional to the event rate in the detector. The variance can be minimized with proper low-pass filtering [1].

The fission chamber is the sensor in a larger system, shown in Figure 3, that includes a preamplifier, a processor, and two outputs, depending on the mode of operation. When in operation, the fission chamber is placed inside the reactor through an instrumentation port, and long cables ( $25 \mathrm{~m}$ or more) are routed to the read-out electronics. Because of this, some form of impedance transformer is required to isolate the logarithmic preamplifier from the cable. For this implementation, a common-base amplifier was used to drive two of these preamplifiers. This provided the impedance match for the cable and provided the high impedance required for proper operation at the input of the logarithmic preamplifier. The preamplifier was resistively terminated into $100 \Omega$ and integrated as part of the logarithmic processor. The complete processor provides two outputs. One goes to a pulse-counting circuit that operates at low rates while individual pulses are distinguishable. As the rate increases, the output becomes a continuum of pulses and results in a varying voltage that is logarithmically proportional to the input count rate. This varying voltage is then input to a direct current (DC) measurement system.

For commercialization, it is recommended a special mineral insulated (MI) cabling is used for the harsh environment of the reactor. This cable was designed with a twisted pair of nickel wires crushed inside a high purity MgO insulator and was contained inside a 0.250 in. stainless steel 316 (SS316) sheath. Most vendors guarantee a $360^{\circ}$ twist per $1 \mathrm{ft}$ or 10 twists in $10 \mathrm{ft}$. Since there is $500 \mathrm{~V}$ applied to this cable, the spacing between the twisted pair wires is a tradeoff between characteristic impedance and voltage standoff. 


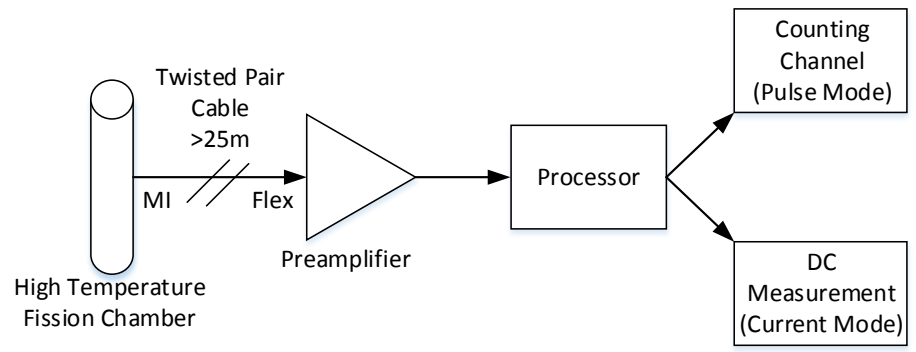

Figure 3. Block diagram of the fission chamber with front-end electronics system [1].

To attach the MI cable to the top of the fission chamber, a custom strain relief mount was machined. The mount screws to the top of the fission chamber and uses a standard Swagelok fitting to secure the MI cable. This mount can be industrialized for commercialization, but it is recommended that the MI cable fabrication company be involved in the design of a commercial connector. Any process that seals the cable must maintain a low moisture content inside the cable. The other end of the MI cable is then connected to a flexible standard safe high voltage (SHV) cable through an SHV connector. The impedance of the cable will depend heavily on the RF cable itself, for example, an RG214 cable has an impedance of $50 \Omega$, and an RG59 has an impedance of $75 \Omega$. Users should be aware of the input impedance of the preamplifier to avoid losses in the cable due to reflections. The standard SHV connector is rated for $50 \mathrm{kV} / 5 \mathrm{~A}$, although not high temperatures. However, the flexibility of the cables allows for easier routing between the instrument and electronics. The MI cable is very rigid because of the SS316 sheath and therefore must be bent using pipe tools. It is important to minimize bends in the cable, and there are limits to how small of a bending degree is allowed. The transition between the MI and SHV cable should be made at a point where the SHV cable can withstand the harsh environment and there are minimal bends in the MI cable.

As mentioned, the electronics must operate across a wide range of flux. At low flux levels (low reactor power), the output of the processor is counting or pulse mode, but as the reactor power increases and reaches a threshold (high reactor power), the output of the processor is a DC measurement or current mode. The design of the processor is critical for this operation to function properly and is discussed in previous reports [1]. The preamplifier design for this application is a trans-impedance amplifier with logarithmic feedback as shown in Figure 4. This causes the output voltage to be proportional to the logarithm of the input current [3]. This design is discussed in detail in the next section of this document.

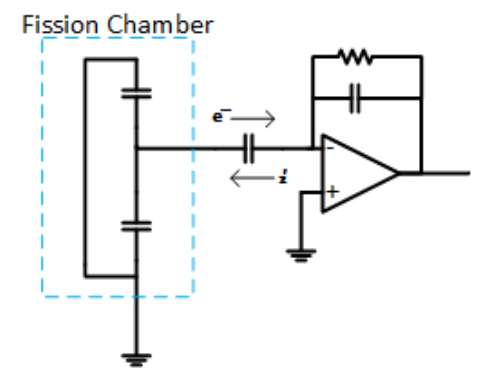

Figure 4. Simplified schematic of the chamber with proposed logarithmic charge-sensitive preamplifier [4]. 


\section{FRONT-END ELECTRONICS}

Because fission chambers have traditionally used preamplifiers located physically away from the detector, coaxial cable of some type is usually employed. Since the signal pulse bandwidths are also usually relatively high, some form of cable termination is important so that signal reflections do not occur. Transimpedance amplifiers [5] are often used because, if appropriately designed, they present an active input impedance that will correctly match the cable capacitance and generate current-to-voltage gain simultaneously.

Because of a very large event-counting range (greater than 9 orders of magnitude), an issue common to most reactor-based fission chambers is the need to compress the event-counting range using a nonlinear approach to data processing. A summary of several published measurement methods is presented in [1]. The major problem with trans-impedance amplifiers is that they generate a linear representation of the count rate and require postprocessing circuitry to generate useful data over the required range. We attempted to develop a technique that combines the input amplifier with the nonlinear processing and were partially successful.

ORNL personnel developed an approach that used a charge-sensitive preamplifier configured with a logarithmic element as part of the feedback path, which results in the output voltage being logarithmically proportional to the input charge. The simplified circuit is illustrated in Figure 4 as a trans-impedance amplifier with a logarithmic feedback element. If a feedback capacitor is added across the feedback element, it looks exactly like a traditional charge-sensitive feedback preamplifier.

One of the obvious problems with this design is that the input impedance is not controlled like a transimpedance amplifier. For very short cables (i.e., a few feet) this is not a problem and is preferred, but for cables measuring tens to hundreds of feet, this can become a problem because the cable itself is part of the feedback circuit.

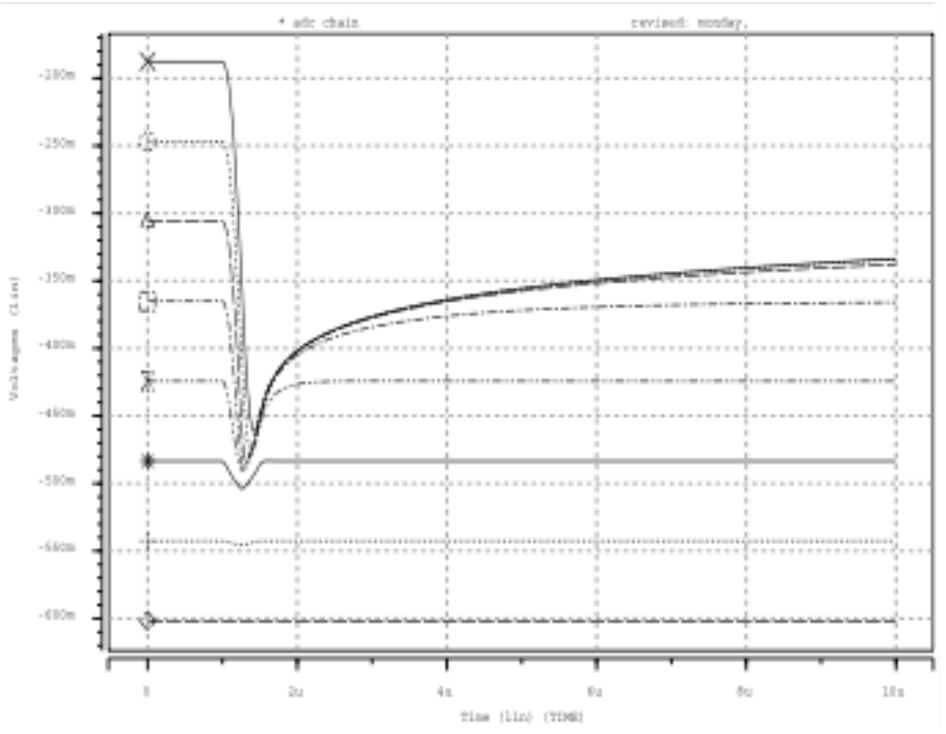

Figure 5. Simulation of logarithmic preamplifier.

A simplified simulation, shown in Figure 5, of a single event superimposed on increasingly larger DC current that shows that as the DC current increases, the pulse amplitude becomes a smaller percentage of 
the overall DC level. This illustrates that, in concept, this technique should be able to be used at low rates as a pulse-counting circuit, and at higher rates where pile up dominates, the DC level can be an indicator of count rate.

Commercially available logarithmic amplifiers are not sufficient for the level of sensitivity required; therefore, custom front-end electronics were developed as shown in Figure 6.

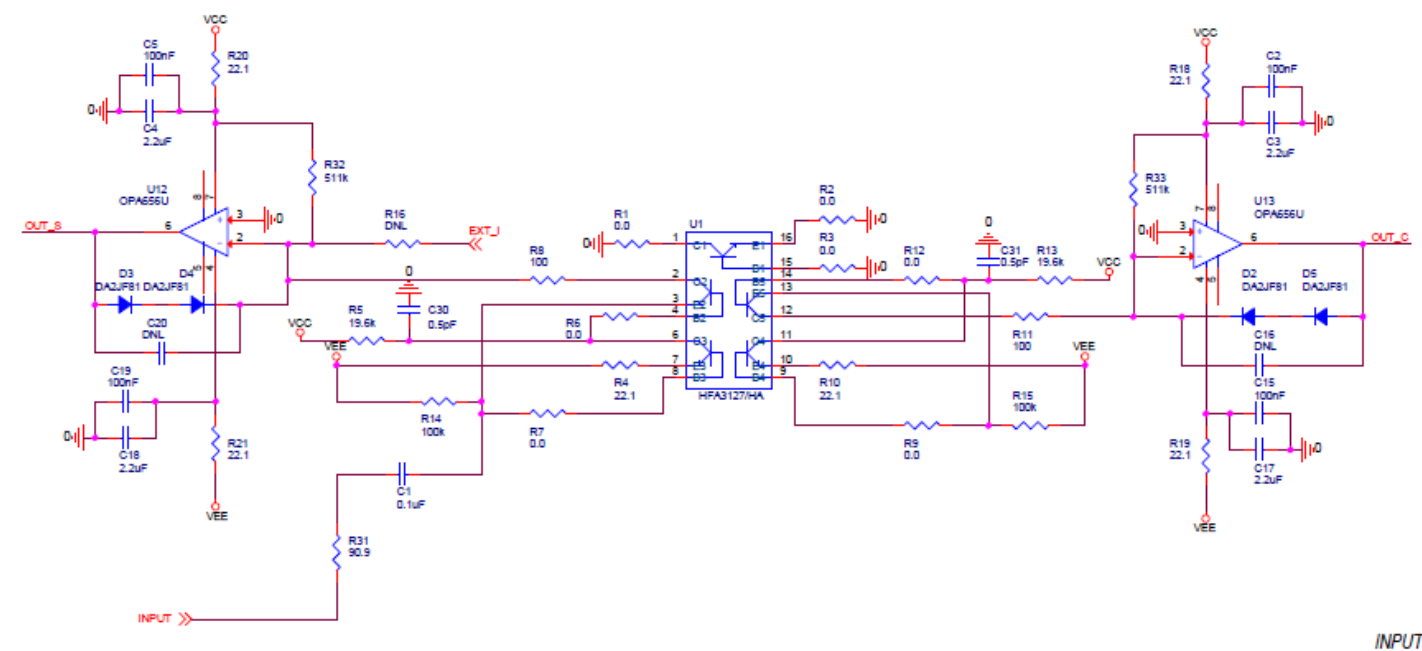

Figure 6. Schematic of front-end electronics.

Simulations were performed using PSpice, and several assumptions were made about the output of the fission chamber (input driving the preamplifier). In the simulation results, displayed in Figure 7, the pulse mode (fast output) results were for a commercial fission chamber and not the HTFC. These simulations were implemented using a commercial fission chamber because at the time of simulations the HTFC was not complete, so the output signal was unknown. Each waveform, from the bottom to the top, corresponds to a signal from a single event superimposed onto a DC current of $1 \mu \mathrm{A}$ (dark blue), $10 \mu \mathrm{A}$ (orange), $100 \mu \mathrm{A}$ (grey), $1 \mathrm{~mA}$ (yellow), and $10 \mathrm{~mA}$ (light blue). Other than the $1 \mu \mathrm{A}$ and $10 \mu \mathrm{A}$ cases, these results do not accurately reflect the performance of a fission chamber in a reactor because the current depends on the rate, and it is unreasonable to expect a single pulse over $10 \mu \mathrm{A}$ of DC current from pulses. However, this is a good demonstration of how the circuit starts in pulse mode for low reactor power and then switches to current mode at higher reactor power. 


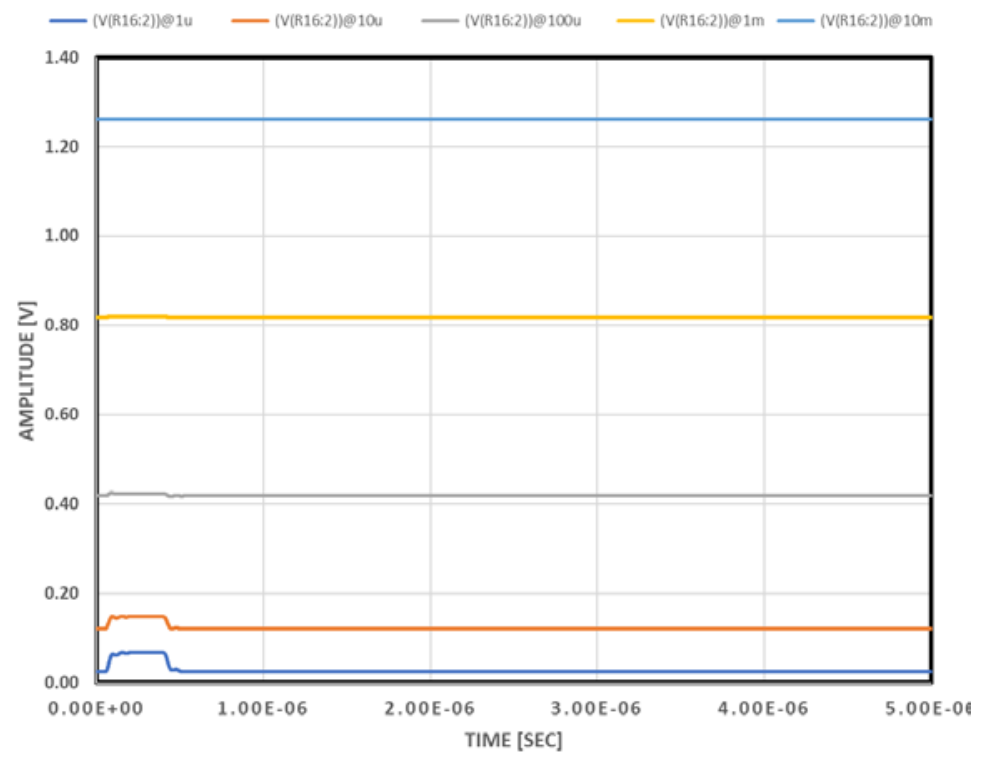

Figure 7. PSpice simulations of electronics with commercial fission chamber.

This circuit was implemented on a custom printed circuit board (Figure 8) and tested at ORNL using commercially available fission chambers. The printed circuit board was housed in a grounded shielding box to help reduce noise on the circuit as shown in Figure 9. Because of the sensitivity of these electronics, they were very susceptible to electromagnetic interference (EMI) from the surrounding environment. Some EMI sources to consider are emanations from pumps, electromagnetic interference from other instrumentation, and ground noise of $120 \mathrm{~V}$ power lines. Shielding and well-designed grounding is critical for operation in an industrial environment. Commercialization of a system like this requires a good understanding of the impact of noise on electronics, noise-canceling techniques, and shielding techniques. The lessons learned from testing with the electronics led to the commercialization plan that is discussed in the next section.

This approach was not entirely successful. During testing, the signal appeared to be large enough for useful processing, but the test setup was unable to reach a high enough event rate to thoroughly test the logarithmic compression function of the preamplifier. The HTFC testing was performed at a reactor and, in the EMI-rich industrial environment, the researchers were unable to obtain a completely clean signal from the electronics. Even though most of it is shielded, the input cable appears to detect a large amount of EMI. An isolation transformer and several other debugging techniques provided little improvement. Possibly, a better input filtering circuit for the lower frequencies may have helped mitigate much of the low-bandwidth EMI sensed by the preamplifier. 


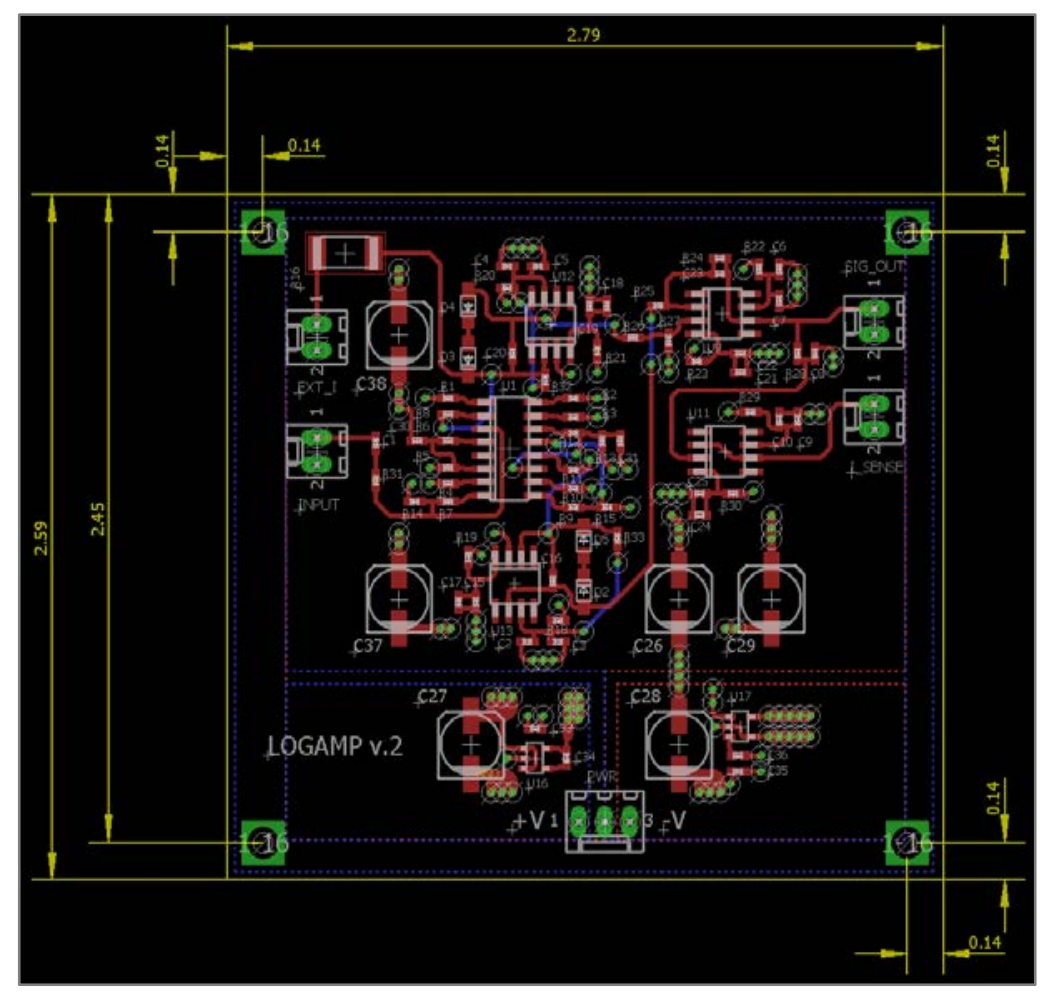

Figure 8. PCB layout of custom front-end electronics.

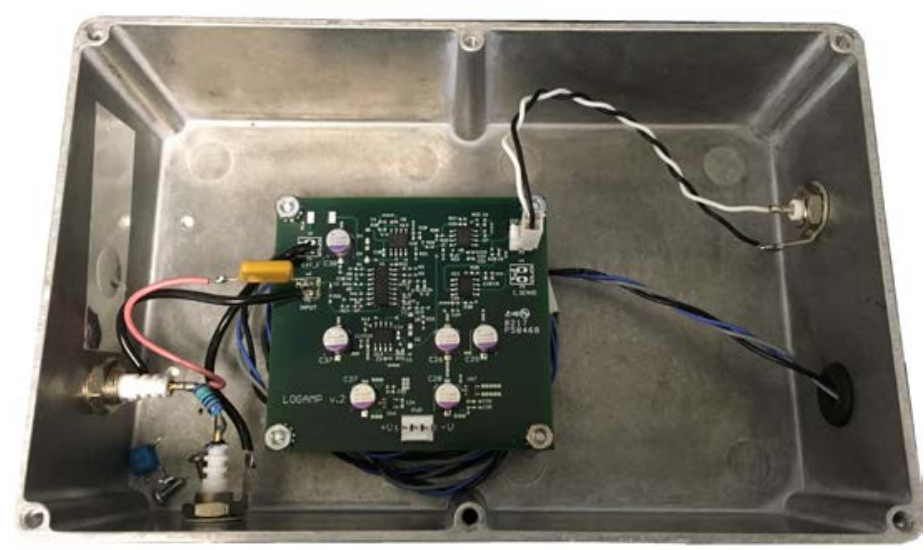

Figure 9. Image of housing containing front-end electronics.

Notably, these electronics were previously tested with both a commercially available fission chamber as well as the HTFC discussed here. Testing in the lab with the commercial fission chamber ensured that the electronics were functioning properly before testing with the HTFC began. Testing with the commercial fission chamber also confirmed the simulation results. This report only discusses the results from testing with the HTFC. 


\section{RECOMMENDATIONS FOR COMMERCIALIZATION}

The initial experiments constitute an important learning activity that can be leveraged to achieve a viable commercialization solution. As shown by the testing effort, commercialization of analog electronics requires a clear understanding of environmental EMI noise and how it impacts the performance of the electronics. The signal level from the output of the front-end electronics depends on the amount of charge acquired from the output of the fission chamber. If the signal is very large compared to the noise levels, the EMI may have little impact on the measurement. However, if the signal is comparable to the noise, on the order of a few hundred millivolts as shown in Figure 10, a high EMI environment can overwhelm the signal and result in a signal-to-noise ratio of much less than unity. Proper packaging and cabling can minimize the impact of EMI on the performance of the electronics. While applying a high voltage of $500 \mathrm{~V}$ to the fission chamber and placing a neutron source nearby, the pulse output signal is approximately $150 \mathrm{mVp}$-p with a decay time of $10 \mu \mathrm{s}$.
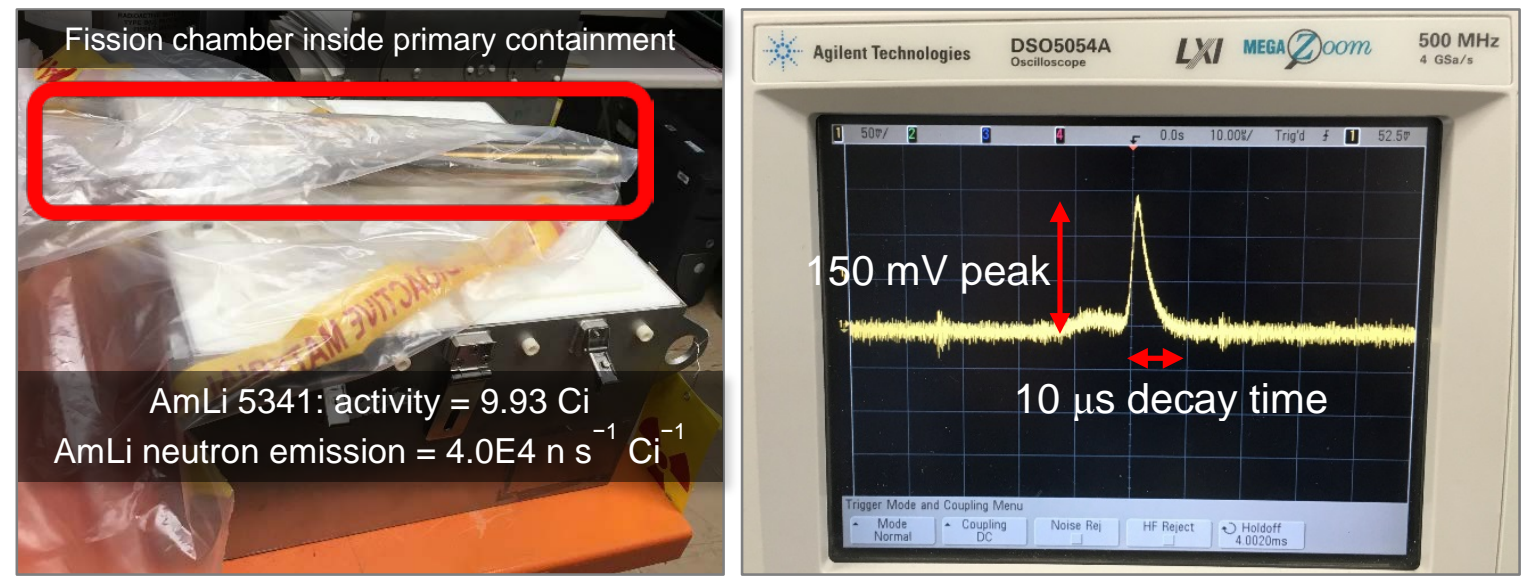

Figure 10. Testing fission chamber performance at ORNL with an AmLi source (100 ft cable) October 2017 [6].

It is obvious that the shielding provided by the electronics housing will be critically important. Since this instrumentation will be installed in a nuclear power plant and will require robustness, the packaging will be required to adhere to the standards required in a plant. Typically, nuclear instrumentation is installed in a rack-mount tower with cabling routed through cable trays. However, some instrumentation is designed in custom cabinetry. ORNL will be pursuing a rack-mount design because, including the integration of a custom linear high-voltage power supply, the overall footprint for the electronics will be very small, and they will fit well in this packaging. Also, only a single cable runs between the fission chamber and electronics. For this reason, the electronics and power supply should be designed to fit inside a standard rack-mount nuclear instrumentation module (NIM) bin as shown in Figure 11. Appropriate shielding and grounding can be applied inside the housing to protect the front-end electronics. A triaxial (triax) cable, as shown in Figure 12, should be used for the signal and voltage. 

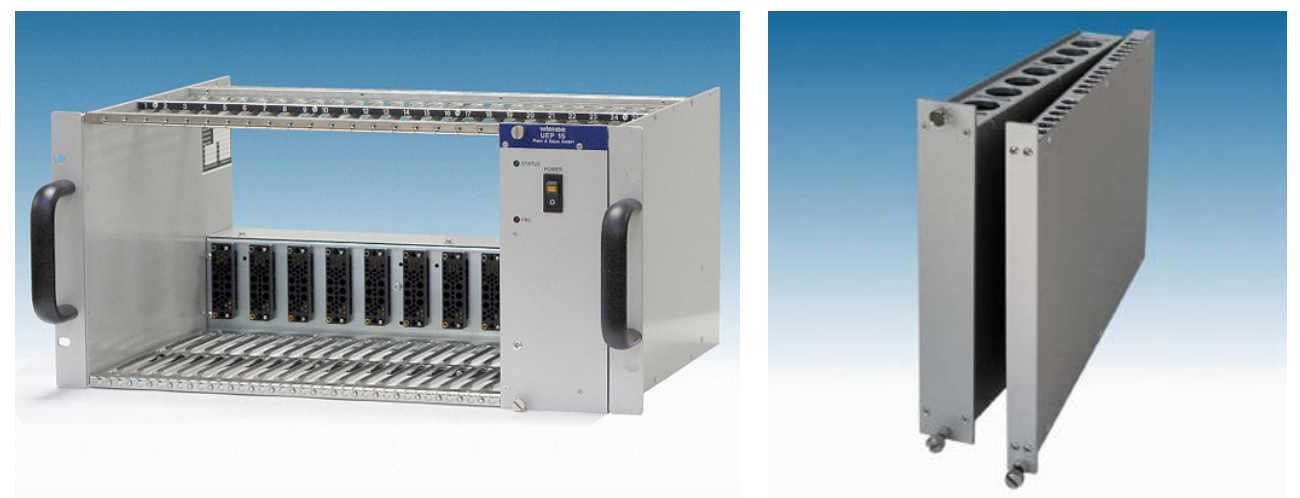

Figure 11. Example NIM bin and module. ${ }^{1}$

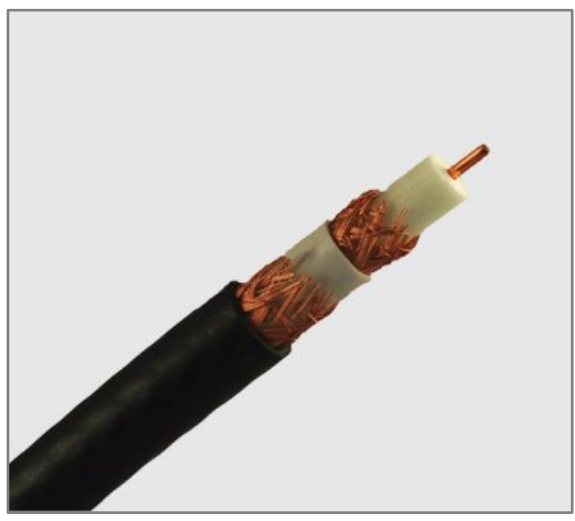

Figure 12. Example triax cable. ${ }^{2}$

Triax cable will provide added shielding and ensure there are two separate grounds: earth ground on the outer sheath and signal ground on the inner sheath. It is important to keep these grounds isolated except at a designated point in the system. This is important because noise injection of cabling is a large problem in industrial environments. Ferrite beads can also be placed on the NIM bin's power cords to attenuate highfrequency electromagnetic noise. Applying multiple commercialization techniques enables the electronic system to be successful in any industrial environment.

\section{DATA ACQUISITION AND SOFTWARE}

For testing at ORNL and the Ohio State University (OSU), a National Instruments (NI) PCI extension for instrumentation (PXI) chassis with several PXI cards, power supplies, and an oscilloscope were used for benchtop testing as shown in Figure 13.s

\footnotetext{
${ }^{1}$ Weiner NIM crates, http://www.wiener-d.com/sc/powered-crates/nim/.

${ }^{2}$ Belden video triax cable, https://www.belden.com/products/enterprise/broadcast-av/cable/video-triax.
} 


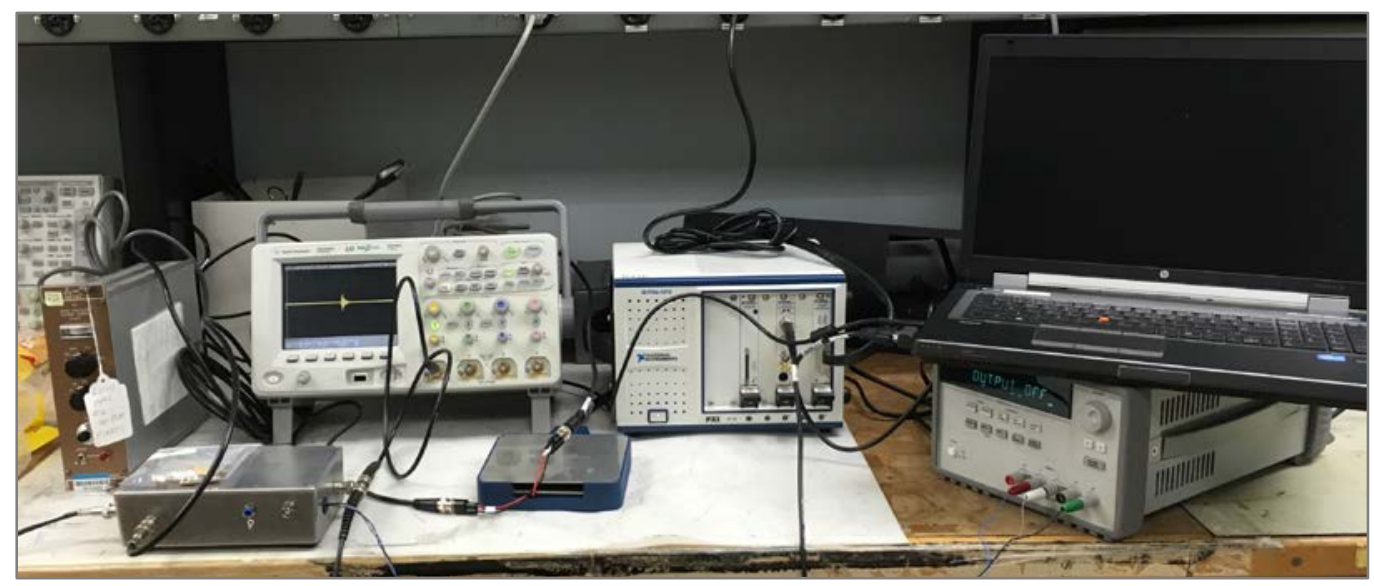

Figure 13. Benchtop data acquisition system.

An Agilent 33522A arbitrary waveform generator was used to simulate the fission chamber pulses. An NI PXI-5122 14-bit digitizer reads the signal while in pulse mode, and an NI PXI-6255 16-bit multi-function I/O module reads the signal while in saturation. The PXI-6255 was also used to output a control voltage to the conditioning electronics. Additionally, the control voltage was read back into the acquisition system to verify the output. The NI PXI cards were installed in an NI PXIe-1073 chassis, which was connected via MXI link to a PC running the NI LabVIEW software.

The data acquisition and control software designed specifically for this project reads the output signal from the fission chamber electronics using the PXI-5122 and PXI-6255 modules. It also communicates via USB with an Agilent DSO5054A $500 \mathrm{MHz}$ oscilloscope to acquire triggered traces of the pulses. The oscilloscope can be configured using the control software for repeatable measurements without user interaction. The fission chamber signal and control voltages may be displayed, or they can be hidden for increased performance. Data acquired from the NI PXI-5122 or the Agilent oscilloscope may be saved to disk for analysis. Although these NI modules are in PXI chassis format, single cards are available for other packaging and can be installed in a NIM bin with the front-end electronics. This commercially available option simplifies data acquisition design. Also, other commercial instrument developers certify NI products for nuclear application.

While running an experiment, there are multiple tabs available to the user in the graphical user interface. The "configuration" and "advanced" tabs are for software controls and are not be available during normal operation. The "configuration" tab allows the user to set the data folder, scope sample rate, and high voltage calibration constant. The "NI PXI" tab allows the user to enable and control the high-voltage output (Figure 14). The user also can enable the scope, then monitor and save real-time data from the PXI-5122 digitizer on this tab. The "Agilent" tab also allows the user to enable, then monitor and save snapshots of data during an experiment as shown in Figure 15. An executable file can be developed and packed for commercialization. This executable would then be open software available through National Instruments. 


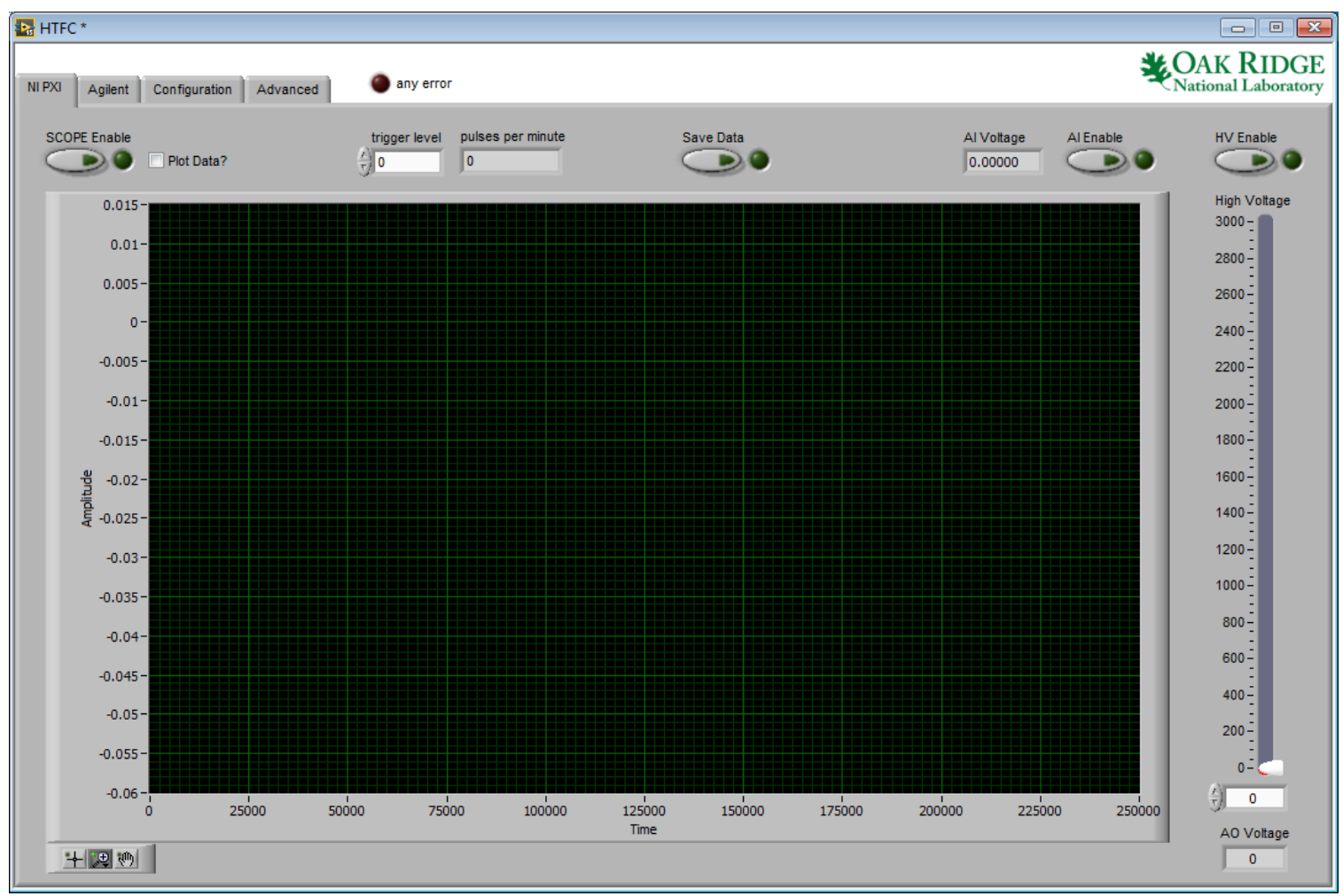

Figure 14. LabVIEW user interface "NI-PXI" tab.

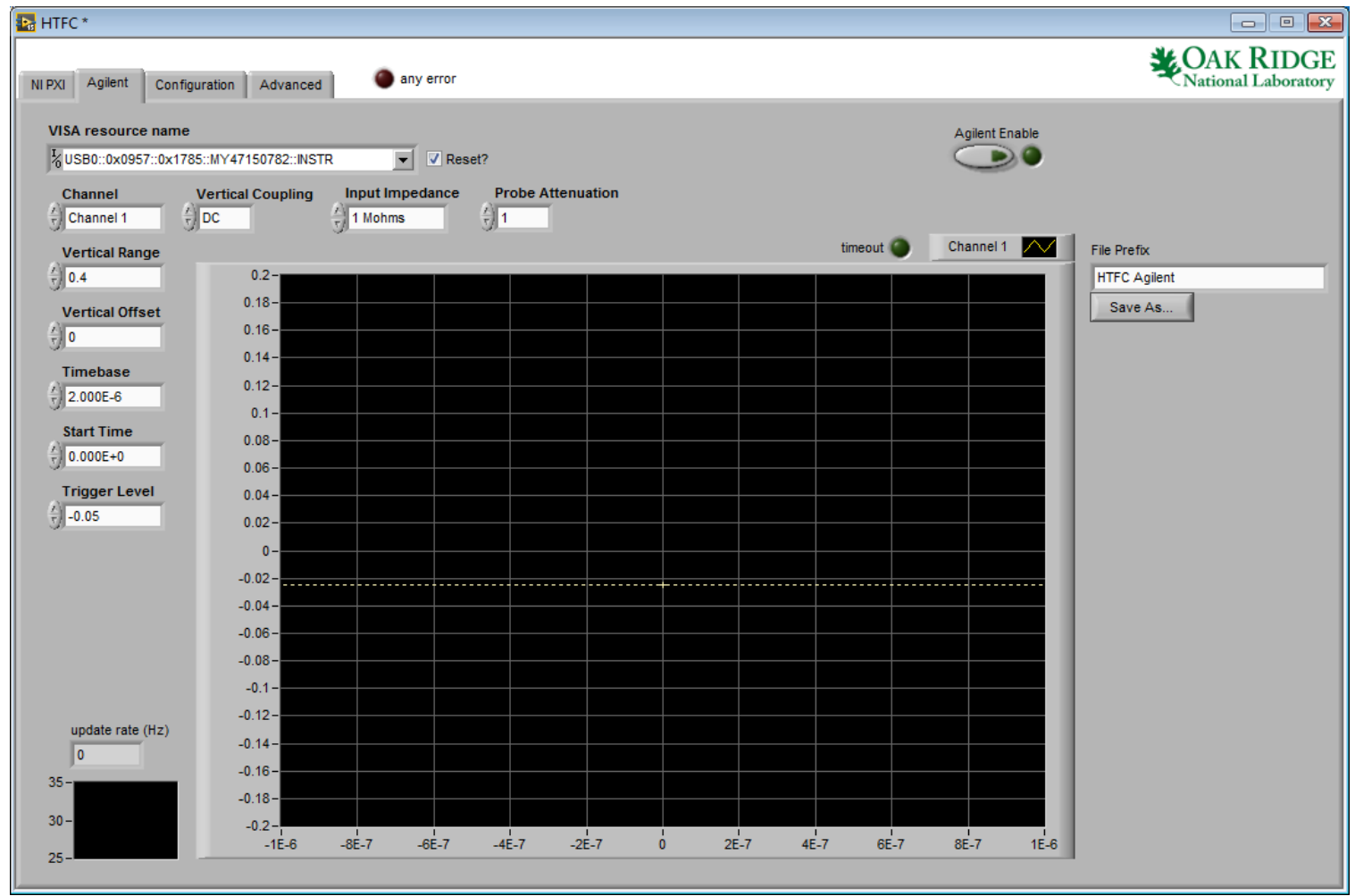

Figure 15. LabVIEW user interface “Agilent” tab. 


\section{CONCLUSIONS}

This document describes ORNL's design of custom front-end electronics that meet the wide range of operation required by the fission chamber. The electronics were previously tested with a commercial fission chamber before testing with ORNL's HTFC. In a laboratory environment, the electronics were capable of detecting pulses from the fission chamber during testing with an AmLi source. Because of the low signal level, the commercialization will be difficult, but possible. Good shielding and grounding, as well as robust packaging, is required. Also, proper cable selection, such as a triax cable, will ensure reduced injected noise on the signal cable. Some other commercialization techniques are discussed and can be applied to this system. Industrial environments are unique and require different solutions for a successful commercial electronics system to survive them. Applying proper techniques will enable the electronic system to be successful in any environment.

\section{REFERENCES}

[1] Z. W. Bell, et al. (2005) "Fission chamber development.” Oak Ridge National Laboratory, Oak Ridge, TN, ORNL/LTR-2012/331.

[2] M. K. Kopp and K. H. Valentine, "Paralleling of preamplifier input stages for a low-noise, wideband termination of low-impedance transmission lines," IEEE Trans. Nucl. Sci., Vol. NS-32, No. 1, Feb. 1985, pp. 68-70.

[3] E. J. Kennedy. Operational Amplifier Circuits: Theory and Applications. (1988).

[4] P. Mulligan, N. D. Ezell, "Development and Planned In-situ Testing of a High Temperature Fission Chamber for Molten Salt and High-temperature Gas Reactors"

[5] Athanasios Papoulis, Probability, Random Variables, and Stochastic Processes, 2nd Ed., McGraw Hill, p. 285.

[6] N. D. Ezell, et al. (2018) Experimental results of the high-temperature fission chamber testing in a harsh environment. Oak Ridge National Laboratory, Oak Ridge, TN, ORNL/TM-2018/802. 